\title{
Ophthalmic survey of a diabetic clinic. I: Ocular findings
}

\author{
R H B GREY, N MALCOLM, D O'REILlY, AND A MORRIS
}

From the Bristol Eye Hospital, Bristol

SUMmARY A medical diabetic clinic was examined for evidence of diabetic eye disease. Of 681 patients invited for ocular examination $96.6 \%$ attended for screening. The results for insulin dependent diabetics (IDDs) and non-insulin dependent diabetics (NIDDs) were analysed separately and the major findings were: (1) Cataracts were present in $40 \cdot 8 \%$ of IDDs and $46 \cdot 2 \%$ of NIDDs, with an increased incidence with advancing age. For younger age groups there were significantly more cataracts in IDDs than in NIDDs $(\mathrm{p}<0.001)$. (2) Cataract extraction was required in $4.2 \%$ of the patients, which is higher than the general population. (3) The presence of retinopathy was related to the duration of diabetes $(\mathrm{p}<0.001)$ but not to age of onset of diabetes. (4) Retinopathy was found in $43.4 \%$ of IDDs and $20.1 \%$ of NIDDs. Sight threatening retinopathy was present in $13.3 \%$ of IDD and $4.3 \%$ of NIDD eyes. (5) Advanced diabetic eye disease was seen in $0.6 \%$ of eyes.

Diabetes mellitus has been shown to affect nearly all tissues of the eye. ${ }^{12}$ Although some effects are mild or temporary with little visual threat, significant loss of vision can occur when patients develop cataracts or diabetic retinopathy.

Within the past decade improvements in therapeutic management of diabetic patients has led to a better visual prognosis, ${ }^{2,17}$ though treatment can be time consuming for both patients and ophthalmologists. ${ }^{18}$

In order to plan treatment services for diabetic patients it is necessary to know the potential work load, which has been estimated as high, possibly to an extent that present services would be unable to cope. A study of patients attending a district general hospital diabetic clinic was undertaken in an attempt to assess the likely work load with which ophthalmologists may be faced. This report is concerned with the ocular findings which were noted during the assessment, and in view of the numbers of patients involved an opportunity was provided to compare insulin dependent diabetics (IDDs) with non-insulin dependent diabetics (NIDDs). Patients were included in IDD or NIDD groups according to their current diabetic treatment rather than on strict insulin dependency.

Correspondence to Mr R H B Grey, FRCS, Bristol Eyc Hospital, Lower Maudlin Strect, Bristol BS1 2LX.

\section{Patients and methods}

A combined medical and ophthalmic clinic was organised for the purpose of this survey, and all patients attending the diabetic clinic at Weston General Hospital during 1981 were invited to attend. The diabetic clinic serves a circumscribed population, pursues a no-discharge policy, and reviews all patients at least once annually.

The patients attending had their corrected visual acuities recorded, slit-lamp examination of the anterior segment and vitreous, and their fundi examined after dilatation of the pupils. All fundus examinations were carried out by one observer (RHBG) using direct and indirect ophthalmoscopy and also contact lens examination in patients with more than minimal retinopathy. Details of the patients' medical and ophthalmic status were recorded on a proforma in order to enable easy transference of data, which were later analysed on the University of Bristol Computer Network.

To facilitate analysis the following criteria were used in the collection of the ophthalmic data:

Cataracts. Grade 0 - no significant opacity; grade 1 -opacity on slit-lamp but clear view of retina with direct ophthalmoscope; grade 2-retinal details partially obscured with direct ophthalmoscope but assessable with indirect ophthalmoscope; grade 3- 
details not accurately assessable with indirect ophthalmoscope; grade 4-aphakia.

Rubeosis iridis. Grade 0-absent; grade 1peripupillary; grade 2-over iris surface.

Retinopathy. Background retinopathy was present if there were microaneurysms, dot haemorrhages, lipid exudates, cotton-wool spots, or microvascular abnormalities consistent with diabetes. Maculopathy was defined as macular oedema, hard exudates threatening the fovea, or foveal ischaemia at the time of the examination, regardless of previous laser treatment. Proliferative retinopathy was diagnosed if there was active vasoproliferation or the presence of fibrovascular tissue but was considered absent if previous treatment had led to complete regression of new vessels. In those patients in whom there was doubt whether there was either maculopathy or early neovascularisation present more detailed assessment, including fluorescein angiography, was performed on a subsequent occasion.

Advanced diabetic eye disease was diagnosed if thrombotic glaucoma, gross retinal ischaemia, traction

Table 1 Age of onset of diabetes

\begin{tabular}{lrrrc}
\hline Age (years) & Male & Female & Both & \% of total \\
\hline$<10$ years & 4 & 6 & 10 & $1 \cdot 5$ \\
$10-19$ & 18 & 15 & 33 & $5 \cdot 0$ \\
$20-29$ & 17 & 8 & 25 & $3 \cdot 8$ \\
$30-39$ & 28 & 12 & 40 & $6 \cdot 1$ \\
$40-49$ & 49 & 37 & 86 & $13 \cdot 1$ \\
$50-59$ & 86 & 63 & 149 & $22 \cdot 7$ \\
$60-69$ & 109 & 88 & 197 & $29 \cdot 9$ \\
$70-79$ & 41 & 63 & 104 & $15 \cdot 8$ \\
80 or over & 4 & 10 & 14 & $2 \cdot 1$ \\
Total & 356 & 302 & 658 & $100 \cdot 0$ \\
\hline
\end{tabular}

Table 2 Age at time of examination for IDDs and NIDDs

\begin{tabular}{lcr}
\hline Age (years) & $I D D(\%)$ & $N I D D(\%)$ \\
\hline$<40$ & $46(22 \cdot 1)$ & $4(0 \cdot 8)$ \\
$40-49$ & $28(13 \cdot 5)$ & $31(6 \cdot 9)$ \\
$50-59$ & $32(15 \cdot 4)$ & $68(15 \cdot 2)$ \\
$60-69$ & $49(23 \cdot 6)$ & $144(32 \cdot 0)$ \\
$70-79$ & $48(23 \cdot 0)$ & $162(36 \cdot 0)$ \\
$80+$ & $5(2 \cdot 4)$ & $41(9 \cdot 1)$ \\
Total & $208(100)$ & $450(100)$ \\
\hline
\end{tabular}

retinal detachment, or phthisis bulbi was present.

\section{Results}

Six hundred and eighty-one patients were asked to attend the combined clinic, of which 658 were examined $(96 \cdot 6 \%)$. Twenty-three patients refused to attend on at least two occasions.

The sex incidence, age of onset of diabetes and type of diabetic treatment are outlined in Tables 1 and 2 . There were 356 males and 302 females. $11 \%$ of males and $10 \%$ of females developed diabetes before the age of 30 , and $13 \%$ of males and $24 \%$ of females were diagnosed after the age of 70 years; in nearly all age groups males outnumbered females. There was a marked difference in the age distribution of IDDs and NIDDs, with the latter being on average much older.

\section{CATARACT}

Slit-lamp examination showed some degree of lens opacity in 538 eyes of 289 patients, and in 103 eyes the opacities were considered to be severe enough to have some influence on vision-that is, grades 2 or 3. Dense cataract, considered to be a potential cause of marked visual loss, was present in only 16 eyes but 48 eyes were already aphakic at the time of examination. In five patients it was recommended that cataract extraction should be undertaken, bilaterally in two cases. At some time, therefore, cataract surgery was considered necessary in a total of 55 eyes $(4.2 \%$ of the total). In three eyes extraction was recommended in order to facilitate laser photocoagulation for retinopathy, which would otherwise have been difficult to perform adequately. Extraction was contraindicated in 12 eyes with severe retinopathy because postoperative improvement in vision was considered unlikely.

Overall, the prevalence of cataract increased with the age of the patients (Table 3 ). When IDDs and NIDDs were analysed separately, it was found that $40.8 \%$ of IDD eyes and $46.2 \%$ of NIDD eyes had some degree of cataract. Although these figures were not significantly different, breakdown into age groups showed insulin dependency was associated

Table 3 Numbers of eyes showing cataracts for IDDs and NIDDs by age at examination

\begin{tabular}{|c|c|c|c|c|c|c|}
\hline \multirow[t]{2}{*}{ Age (years) } & \multicolumn{2}{|l|}{$I D D s$} & \multicolumn{2}{|l|}{ NIDDs } & \multirow[t]{2}{*}{$x^{2}$} & \multirow[t]{2}{*}{$p$} \\
\hline & No cataract (\%) & Cataract (\%) & No cataract $(\%)$ & Cataract $(\%)$ & & \\
\hline$<50$ & $124(83 \cdot 8)$ & $24(16 \cdot 2)$ & $70(100)$ & $0(0.0)$ & $11 \cdot 154$ & $<0 .(0) 1$ \\
\hline $50-59$ & $37(57.9)$ & $27(42 \cdot 1)$ & $114(83 \cdot 8)$ & $22(16 \cdot 2)$ & $14 \cdot 543$ & $<0.001$ \\
\hline $60-69$ & $62(63 \cdot 3)$ & $36(36 \cdot 7)$ & $185(64 \cdot 5)$ & $102(35 \cdot 5)$ & $0 \cdot 008$ & NS \\
\hline $70+$ & $23(21 \cdot 7)$ & $83(78 \cdot 3)$ & $114(28 \cdot 1)$ & $292(71.9)$ & 1.436 & NS \\
\hline Total & $246(59 \cdot 2)$ & $170(40 \cdot 8)$ & $483(53 \cdot 8)$ & $416(46 \cdot 2)$ & $3 \cdot 152$ & NS \\
\hline
\end{tabular}


Table 4 Severity of cataracts for IDDs and NIDDs by age at examination

\begin{tabular}{|c|c|c|c|c|c|c|}
\hline \multirow[t]{2}{*}{ Age (years) } & \multicolumn{2}{|l|}{$I D D s$} & \multicolumn{2}{|l|}{$N I D D s$} & \multirow[t]{2}{*}{$\chi^{2}$} & \multirow[t]{2}{*}{$p$} \\
\hline & Grade 0-2(\%) & Grade $3 \& 4(\%)$ & Grade 0-2(\%) & Grade $3 \& 4(\%)$ & & \\
\hline$<50$ & $144(97 \cdot 3)$ & $4(2 \cdot 7)$ & $70(100)$ & $0(0 \cdot 0)$ & 0.719 & NS \\
\hline $50-59$ & $61(95 \cdot 3)$ & $3(4 \cdot 7)$ & $134(98 \cdot 5)$ & $2(1.5$ & 0.764 & NS \\
\hline $60-69$ & $88(89 \cdot 8)$ & $10(10 \cdot 2)$ & $276(96 \cdot 2)$ & $11(3 \cdot 8)$ & $4 \cdot 581$ & $<0.05$ \\
\hline $70+$ & $98(92 \cdot 5)$ & $8(7 \cdot 5)$ & $380(93 \cdot 6)$ & $26(6 \cdot 4)$ & 0.041 & NS \\
\hline Total & $391(94 \cdot 0)$ & $25(6 \cdot 0)$ & $860(95 \cdot 5)$ & $39(4 \cdot 5)$ & $1 \cdot 374$ & NS \\
\hline
\end{tabular}

Table 5 Prevalence of cataract in men and women for IDDs and NIDDs

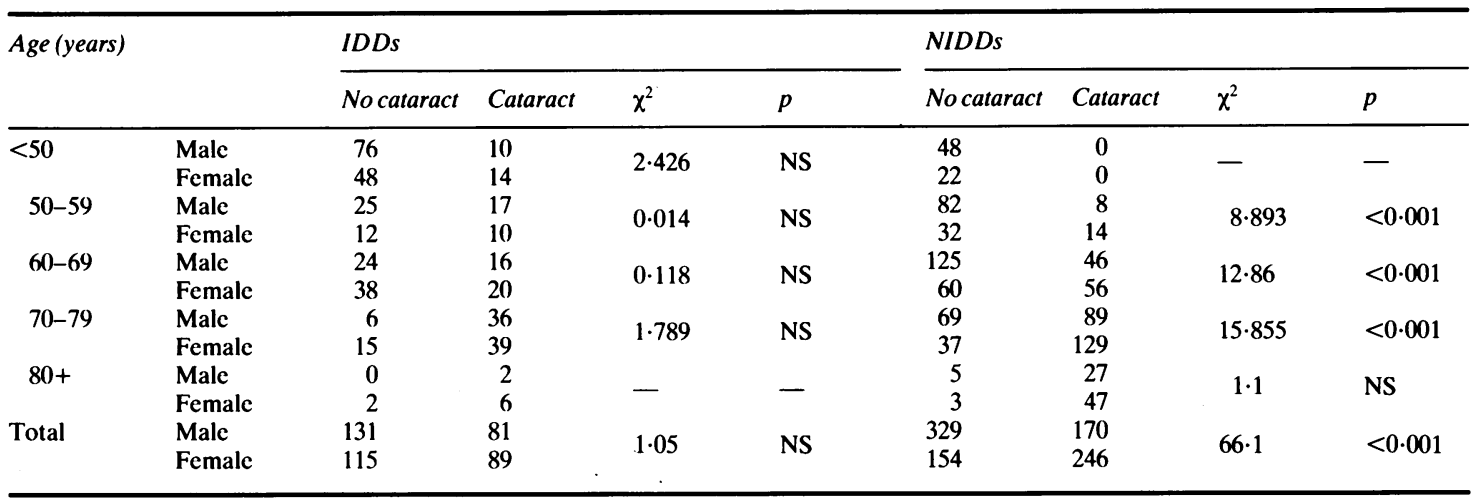

Table 6 Prevalence of cataract for IDDs and NIDDs with and without retinopathy

\begin{tabular}{|c|c|c|c|c|c|c|c|}
\hline & \multicolumn{2}{|c|}{ No retinopathy } & \multicolumn{2}{|l|}{ Retinopathy } & \multirow[t]{2}{*}{$\chi^{2}$} & \multirow[t]{2}{*}{$p$} & \multirow{2}{*}{$\begin{array}{l}\text { Not } \\
\text { known }\end{array}$} \\
\hline & Cataract $(\%)$ & No cataract $(\%)$ & Cataract $(\%)$ & No cataract $(\%)$ & & & \\
\hline IDD & $73(31 \cdot 3)$ & $160(68 \cdot 7)$ & $93(52 \cdot 0)$ & $86(48 \cdot 0)$ & $17 \cdot 05$ & $<0.001$ & 4 \\
\hline NIDD & $314(44 \cdot 2)$ & $397(55 \cdot 8)$ & $93(52 \cdot 0)$ & $86(48 \cdot 0)$ & $3 \cdot 192$ & NS & 9 \\
\hline Total & $387(41 \cdot 0)$ & $557(59.0)$ & $186(52 \cdot 0)$ & $172(48 \cdot 0)$ & & & 13 \\
\hline
\end{tabular}

Four IDD and nine NIDD eyes: retinopathy could not be assessed. All 13 eyes had cataract.

with a higher rate of cataract development for patients less than 60 years of age $(p<0.001)$ but not in patients of 60 years or more.

Dense cataract was not found to be significantly different for IDDs and NIDDs at any age with the exception of the 60-69 year age group, in which a higher proportion of IDDs had dense opacities $(\mathrm{p}<0.05)$ (Table 4).

Cataract was found to be more common in females than males for the NIDD patients, and this difference was present in each age group (Table 5). There was no significant difference in the prevalence or severity of cataract for males and females among IDD patients nor severity of cataract in NIDDs.

Eyes with retinopathy showed a higher incidence of cataracts for IDD patients $(p<0.01)$, but no significant difference was found for NIDD patients (Table 6). Proliferative retinopathy was not associ- ated with a significantly higher rate of cataract than in eyes with non-proliferative retinopathy.

VITREOUS DETACHMENT AND HAEMORRHAGE

Identifiable detachment of the posterior hyaloid was seen in 437 eyes $(33.2 \%)$, but examination for detachment of the posterior hyaloid was not possible in 45 eyes on account of media opacities, advanced diabetic eye disease, or previous vitrectomy (Table 7). The great majority of involved eyes showed the typical vitreous configuration of senile separation. For both IDD and NIDD patients there was an increase in the percentage showing posterior vitreous separation with age $(17 \%$ for those less than 50 years old rising to about $40 \%$ for those of 70 years and over).

In eyes with retinopathy a highly significant increase in vitreous detachment was found for IDDs 
Table 7 Prevalence of vitreous detachment in IDDs and NIDDs by age at examination

\begin{tabular}{|c|c|c|c|c|c|c|c|}
\hline \multirow{2}{*}{$\begin{array}{l}\text { Age } \\
\text { (years) }\end{array}$} & \multicolumn{2}{|l|}{$I D D s$} & \multicolumn{2}{|l|}{$N I D D s$} & \multirow[t]{2}{*}{$\chi^{2}$} & \multirow[t]{2}{*}{$p$} & \multirow{2}{*}{$\begin{array}{l}\text { Not } \\
\text { known }\end{array}$} \\
\hline & No PVD (\%) & $P V D(\%)$ & No PVD (\%) & $P V D(\%)$ & & & \\
\hline$<50$ & $117(82 \cdot 4)$ & $25(17 \cdot 6)$ & $58(82 \cdot 9)$ & $12(17 \cdot 1)$ & 0.0 & NS & 6 \\
\hline$<50-59$ & $45(72 \cdot 6)$ & $17(27 \cdot 4)$ & $108(81 \cdot 8)$ & $24(18 \cdot 2)$ & $1 \cdot 641$ & NS & 6 \\
\hline 60-69 & $49(52 \cdot 1)$ & $45(47 \cdot 8)$ & $183(64.9)$ & - $\quad 99(35 \cdot 1)$ & $4 \cdot 337$ & $<0.05$ & 10 \\
\hline $70+$ & $63(61 \cdot 2)$ & $40(38 \cdot 8)$ & $211(54 \cdot 7)$ & $175(45 \cdot 3)$ & $1 \cdot 114$ & NS & 23 \\
\hline Total & $274(68 \cdot 3)$ & $127(31 \cdot 7)$ & $560(64 \cdot 4)$ & $310(35 \cdot 6)$ & $1 \cdot 738$ & NS & 45 \\
\hline
\end{tabular}

$\mathrm{PVD}=$ Posterior vitreous detachment.

Table 8 Vitreous detachment in eyes with and without retinopathy for IDDs and NIDDs

\begin{tabular}{|c|c|c|c|c|}
\hline & \multicolumn{2}{|l|}{$I D D s$} & \multicolumn{2}{|l|}{$N I D D s$} \\
\hline & No retinopathy & Retinopathy & No retinopathy & Retinopathy \\
\hline No PVD & $177(77 \cdot 6)$ & $97(56 \cdot 1)$ & $450(64 \cdot 3)$ & $110(65 \cdot 1)$ \\
\hline PVD & $51(22 \cdot 4)$ & $76(43.9)$ & $250(35 \cdot 7)$ & $59(34.9)$ \\
\hline Total & $228(100 \cdot 0)$ & $173(100 \cdot 0)$ & $700(100 \cdot 0)$ & $169(100 \cdot 0)$ \\
\hline$\chi^{2}$ & \multirow{3}{*}{\multicolumn{2}{|c|}{$\begin{array}{l}20 \cdot 15 \\
<0 \cdot 001 \\
15\end{array}$}} & \multirow{3}{*}{\multicolumn{2}{|c|}{$\begin{array}{l}0 \cdot 01 \\
\text { NS } \\
30\end{array}$}} \\
\hline$\hat{p}$ & & & & \\
\hline Not classifiable & & & & \\
\hline
\end{tabular}

PVD=Posterior vitreous detachment.

Table 9 Eyes showing retinopathy in IDDs and NIDDs by duration of diabetes

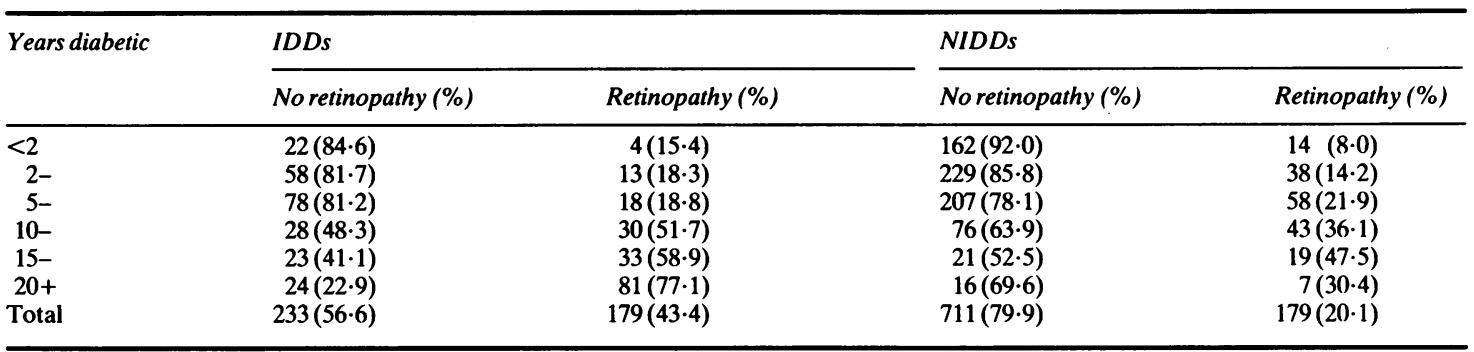

In four IDD and nine NIDD eyes the presence of retinopathy could not be determined.

$(\mathrm{p}<0 \cdot 001)$. This was not true for NIDDs (Table 8). Eyes with proliferative retinopathy showed vitreous detachment in all but two cases, in which there were flat new vessels arising in the retinal periphery.

Vitreous haemorrhage was present in 12 eyes $(0.9 \%)$. Six IDDs had vitreous haemorrhage, of which five had had diabetes for over 20 years and one case bled between two and five years. Vitreous haemorrhage tended to occur earlier in NIDDs, with one before two years after the diagnosis of diabetes, two between two and five years, one between five and 10 years, and one between 15 and 20 years. Vitrectomy was recommended in six eyes, but in the remaining six eyes surgery was not recommended as it was considered that either the blood would clear spontaneously or that the diabetic retinopathy was - too advanced for visual improvement.

In 15 eyes $(1 \cdot 1 \%)$ cataract or advanced diabetic eye disease prevented assessment of the presence of vitreous haemorrhage.

\section{RETINOPATHY}

Retinopathy was present in 358 eyes $(27 \cdot 2 \%)$ of 200 patients $(30 \cdot 3 \%)$. The prevalence of retinopathy in IDDs and NIDDs related to the duration of the diabetes is shown in Table 9. For both IDDs and NIDDs the proportion of patients with retinopathy tended to increase with duration of diabetes and this trend was highly significant $(p<0 \cdot 001)$. Only 23 NIDDs had diabetes for 20 years or more (Fig. 1). However, age of onset was found to be of less significance than duration of diabetes with regard to the prevalence of retinopathy (Table 10).

There was no difference in the prevalence of retinopathy for males or females in either IDDs or NIDDs in any age group. In 13 eyes the presence of 


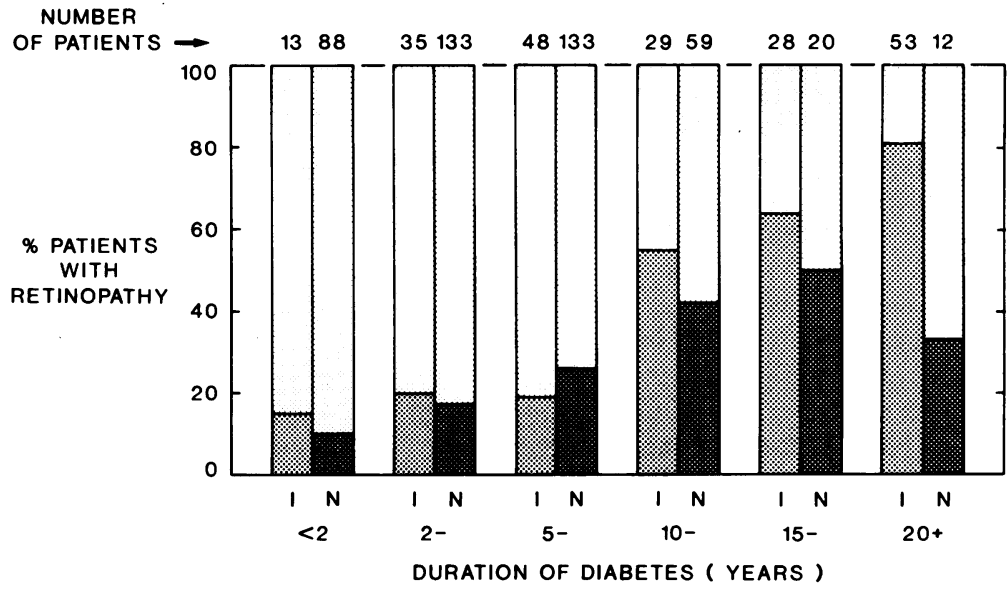

Fig. 1 Histogram showing percentage of patients with retinopathy related to duration of diabetes.

I=INSULIN DEPENDENT $N=$ NON-INSULIN DEPENDENT

retinopathy could not be determined because of opacities in the media.

In 358 eyes with retinopathy, only background changes were present in $267(20.3 \%$ of all eyes and $74.6 \%$ of retinopathic eyes). The serious forms of retinopathy, namely maculopathy and proliferative retinopathy, are listed in Table 11 . The prevalence of both background and serious retinopathy was higher in IDD than NIDD patients. In IDDs 127 eyes (30.8\%) had background and 47 eyes $(11.3 \%)$ had serious retinopathy, whereas in NIDDs 140 eyes $(15.7 \%)$ had background and $38(4.3 \%)$ serious retinopathy. If only those eyes with microangiopathy were considered, the difference in prevalence of serious retinopathy between IDDs and NIDDs was much less- $26 \cdot 3 \%$ of IDDs and $21.2 \%$ of NIDDs.
In 38 patients $(5.8 \%)$ retinopathy was present in only one eye. In one case the retinopathy had progressed to maculopathy, but in all the remaining 37 cases background changes only were present. No patients in the study had proliferative retinopathy or advanced diabetic eye disease in one eye without some microvascular changes in the fellow eye.

One hundred and fifty-eight patients had retinopathy in both eyes. Of these 103 had background changes only bilaterally. Twenty-two patients had background retinopathy in one eye with serious retinopathy in the fellow eye (15 with maculopathy, six with vasoproliferation, and one advanced diabetic eye disease). Thirty patients had bilateral serious retinopathy and two had serious retinopathy in one eye with advanced disease in the other. One patient had advanced eye disease in both eyes.

Table 10 Prevalence of retinopathy by age of onset of diabetes

\begin{tabular}{|c|c|c|c|c|c|}
\hline \multirow{2}{*}{$\begin{array}{l}\text { Duration of diabetes } \\
\text { (years) }\end{array}$} & \multirow{2}{*}{$\begin{array}{l}\text { Age of onset of } \\
\text { diabetes (years) }\end{array}$} & \multicolumn{2}{|l|}{$I D D s$} & \multicolumn{2}{|l|}{$N I D D s$} \\
\hline & & No retinopathy & Retinopathy (\%) & No retinopathy & Retinopathy (\%) \\
\hline \multirow[t]{3}{*}{$<10$} & $<40$ & 52 & $2(3.7)$ & 10 & $4(28 \cdot 6)$ \\
\hline & $40-59$ & 53 & $15(22 \cdot 1)$ & 194 & $36(15 \cdot 7)$ \\
\hline & $60+$ & 53 & $18(25 \cdot 4)$ & 394 & $70(15 \cdot 1)$ \\
\hline \multirow[t]{3}{*}{$10+$} & $<40$ & 38 & $87(69 \cdot 6)$ & 13 & $7(35 \cdot 0)$ \\
\hline & $40-59$ & 25 & $51(67 \cdot 1)$ & 59 & $35(37 \cdot 2)$ \\
\hline & $60+$ & 12 & $6(33 \cdot 3)$ & 41 & $27(39 \cdot 7)$ \\
\hline
\end{tabular}

Table 11 Severity of retinopathy (with percentages) for IDD and NIDD eyes

\begin{tabular}{lllllc}
\hline & Nil $(\%)$ & Background only $(\%)$ & Maculopathy $(\%)$ & Proliferative $(\%)$ & Advanced $(\%)$ \\
\hline IDD & $233(56 \cdot 6)$ & $127(30 \cdot 8)$ & $32(7 \cdot 8)$ & $24(5 \cdot 8)$ & $9(2 \cdot 2)$ \\
NIDD & $711(79 \cdot 9)$ & $140(15 \cdot 7)$ & $31(3 \cdot 5)$ & $9(1 \cdot 0)$ & $1(0 \cdot 1)$ \\
Total & $944(72 \cdot 5)$ & $267(20 \cdot 5)$ & $63(4 \cdot 8)$ & $33(2 \cdot 5)$ & $10(0 \cdot 8)$ \\
\hline
\end{tabular}

In four IDD and nine NIDD cyes the presence of retinopathy could not be determined. 
RUBEOSIS IRIDIS AND ADVANCED DIABETIC EYE DISEASE

Rubeosis iridis was not a common finding. Ten eyes were seen with fine vessels around the pupil margin, and three eyes had rubeosis extending over the whole iris surface. Gonioscopy was not undertaken to examine the drainage angle for signs of peripheral new vessels.

Advanced diabetic eye disease was seen in less than $1 \%$ of eyes. Two eyes showed gross retinal ischaemia without signs of proliferative retinopathy, five eyes had traction retinal detachments, one eye had thrombotic glaucoma, and two eyes had become phthisical.

\section{CONCOMITANT EYE DISEASE}

One hundred and sixty-eight eyes of 122 patients showed ocular disorders other than diabetes which were considered serious enough to have affected vision to some degree (Table 12). No relative quantitative assessment of visual loss was undertaken in these patients, but in many cases the concomitant disorder was of greater visual significance than the diabetic retinopathy. The prevalence of retinopathy in eyes with myopia and chronic simple glaucoma was lower than the prevalence in the remainder of the series.

\section{Discussion}

\section{CATARACT}

The prevalence of cataract in the diabetic population has been reported as varying from $6 \%$ to $45 \%$, with increasing age showing a marked effect on the figures. ${ }^{1920}$

Caird $^{20}$ has excellently reviewed the subject of epidemiology of cataracts in diabetes. The absence of non-diabetic patients in this study precludes firm inferences on the role of diabetes in the development of cataract. The figures concur with previous reports of a lower incidence in younger than older patients-

Table 12 Eyes with concomitant ocular disease

\begin{tabular}{lllr}
\hline & Number & $\begin{array}{l}\text { No. with } \\
\text { retinopathy }\end{array}$ & $\%$ \\
\hline Senile macular atrophy & 43 & 11 & $25 \cdot 6$ \\
Myopia & 33 & 5 & $15 \cdot 2$ \\
Chronic simple glaucoma & 23 & 2 & $8 \cdot 7$ \\
Ambolyopia & 18 & 4 & $22 \cdot 2$ \\
Disciform macular degeneration & 10 & 1 & $10 \cdot 0$ \\
Corneal scarring & 10 & 3 & $30 \cdot 0$ \\
Preretinal traction membrane & 7 & 4 & $57 \cdot 1$ \\
Ischaemic optic neuropathy & 5 & 1 & $20 \cdot 0$ \\
Uveitis & 5 & 0 & - \\
Branch vein occlusion & 3 & 0 & - \\
Central vein occlusion & 3 & 0 & - \\
Miscellaneous & 8 & 1 & $12 \cdot 5$ \\
\hline
\end{tabular}

that is, $9 \%$ in those under 40 years rising to $89 \%$ in those over 80 years-but whether diabetes is a major influence on this increase with age has been questioned. ${ }^{2021}$ The current study showed that the prevalence of cataract in IDDs was significantly higher than in NIDDs less than 60 years of age but not in the older age groups.

Cataract extraction was recommended for seven eyes and had already been undertaken previously in 48 eyes. This resulting high extraction rate of $4 \cdot 2 \%$ is in agreement with previous reports in diabetic patients $\mathrm{s}^{22}$ and is higher than might be expected in the general population. ${ }^{23}$

The presence of known diabetic involvement of the eye (i.e., retinopathy) appeared to have some association with the presence of cataracts in IDDs; $52.6 \%$ of patients with retinopathy had cataracts compared with $38.2 \%$ of patients without retinopathy $(\mathrm{p}<0 \cdot 01)$. The difference was much smaller in NIDDs, $22.4 \%$ and $18.5 \%$ respectively, and was not statistically significant. This finding together with the high prevalence rate of both cataract and retinopathy in IDDs might suggest some common pathogenetic factors for both these diabetic complications.

\section{RETINOPATHY}

It has been established that retinopathy, potentially the most serious of the ocular complications of diabetes and one of the most debilitating generally, becomes more prevalent as the duration of the disease increases. ${ }^{12431}$

This study concurs with these findings. Previous reports have tended to consider IDDs alone or all types of diabetes together and suggested that the prevalence of retinopathy rose from about $15 \%$ at five years to $60 \%$ at 15 years and $75 \%$ at 20 years.

Donovan, in a prospective study, ${ }^{32}$ showed an overall incidence of retinopathy in his diabetic patients of $22.7 \%$, which was slightly lower than the $30.3 \%$ of the present study. He used direct ophthalmoscopy only, and this may account for the slightly lower figure. ${ }^{29}$ Unfortunately his work could not be completed and the precise ophthalmic details were not published. It was thought that $6 \cdot 1 \%$ of patients had maculopathy ( $4.9 \%$ of eyes in the present study) and $4.4 \%$ had proliferative changes $(2.5 \%$ in the present study). Only one-third of Donovan's patients with retinopathy had previously attended an ophthalmologist; thus his slightly higher figures for the more severe forms of retinopathy may be a result of fewer referrals for photocoagulation.

Scobie et al. ${ }^{18}$ reviewed 1000 consecutive diabetic patients attending a diabetic clinic. They found $26.7 \%$ had retinopathy and $9.5 \%$ had serious retinopathy - that is, maculopathy, proliferative changes, or signs of retinal ischaemia. The latter group was not 
categorised in this survey, but Scobie found roughly equal numbers of maculopathy and proliferative patients. This contrasts with the present findings of maculopathy being twice as common as neovascularisation, though there was no gross difference in the age structure or diabetic treatment of the patients in the two studies.

Analysis of the treatment groups separately showed that proliferative retinopathy was almost six times more common and maculopathy was twice as common in IDDs as in NIDDs. Although this association in proliferative retinopathy is well recognised, the latter finding was not expected. ${ }^{33}$ The much larger number of patients not requiring insulin has led presumably to the impression of maculopathy being more common by weight of numbers.

Advanced diabetic eye disease was found in only $0.6 \%$ of eyes. This low figure may be a reflection of the efficacy of photocoagulation, which had been already carried out on a number of the patients. ${ }^{34}$ However, 23 patients failed to attend for examination, and it is likely that some of these cases did so because they already had severe ocular complications of diabetes.

The authors would like to thank Miss E Weekes, Miss P Storey and Mrs B Court for their considerable help in running the survey clinics, and Mrs D Archer for preparation of the manuscript.

\section{References}

1 Caird FI, Pirie A, Ramsell TG. Diabetes and the eye. Oxford: Blackwell, 1969: 127-39.

2 Duke-Elder S. System of ophthalmology. London: Kimpton, 1976; 15: 44-6.

3 Cheng H. Response of proliferative diabetic retinopathy to xenon arc photocoagulation. Trans Ophthalmol Soc UK 1976; 96: 224-7.

4 Diabetic Retinopathy Study Research Group. Preliminary reports on effects of photocoagulation therapy. Am J Ophthalmol 1976; 81: 383-96.

5 British Multicentre Photocoagulation Trial. Proliferative diabetic retinopathy: treatment with xenon arc photocoagulation. Br Med J 1977; i: 739-41.

6 Hercules BL, Gayed II, Lucas, JB, Jeacock J. Peripheral retinal ablation in the treatment of proliferative diabetic retinopathy: a 3 year intensive report of randomised, controlled study using argon laser. Br J Ophthalmol 1977; 61: 555-63.

7 Hamilton AM. Diabetic blindness and its prevention by photocoagulation. Trans Ophthalmol Soc UK 1978; 98: 296-8.

8 Diabetic Retinopathy Study Research Group. Photocoagulation treatment of proliferative diabetic retinopathy. Ophthalmology (Rochester) 1978; 85: 82-106.

9 Michels RG. Vitrectomy for complications of diabetic retinopathy. Arch Ophthalmol 1978; 96: 237-46.

10 Townsend C, Bailey J, Kohner EM. Xenon arc photocoagulation in the treatment of diabetic maculopathy. Trans Ophthalmol Soc UK 1979; 99: 13-6.

11 Aaberg TM. Clinical results in vitrectomy for diabetic traction retinal detachment. Am J Ophthalmol 1979; 88: 246-53.
12 Yassur Y, Pickle LW, Fine SL, Singerman L, Orth DM, Patz A. Optic disc neovascularisation in diabetic retinopathy. II. Natural history and results of photocoagulation treatment. $\mathrm{Br} J$ Ophthalmol 1980; 64: 77-86.

13 Townsend C, Bailey J, Kohner E. Xenon arc photocoagulation for the treatment of diabetic maculopathy. Br J Ophthalmol 1980; 64: 385-91.

14 Hamilton AM, Townsend C, Khoury D, Gould E, Blach RK. Xenon arc and argon laser photocoagulation in the treatment of diabetic disc neovascularisation. Trans Ophthalmol Soc UK 1981; 101: 87-92.

15 Reeser F, Fleischman J, Williams GA, Goldman A. Efficacy of argon laser photocoagulation in the treatment of circinatc diabetic retinopathy. Am J Ophthalmol 1981; 92: 762-7.

16 Plumb AP, Swan AV, Chignell AH, Shilling JS. A comparative trial of xenon arc and argon laser photocoagulation in the treatment of proliferative diabetic retinopathy. BrJ Ophthalmol 1982; 66: 213-8.

17 Shea M. Early vitrectomy in proliferative diabetic retinopathy. Arch Ophthalmol 1983; 101: 1204-5.

18 Scobie IN, MacCuish AC, Barrie T, Green FD, Foulds WS. Serious retinopathy in a diabetic clinic: prevalence and therapeutic implications. Lancet 1981; ii: 520-1.

19 Burditt AF, Caird FI. Natural history of lens opacities in diabetics. Br J Ophthalmol 1968; 52: 433-40.

20 Caird FI. Problems of cataract epidemiology with special reference to diabetes. In: The human lens in relation to cataract. Ciba Foundation Symposium. Amsterdam: Excerpta Medica, Associated Scientific Publishers, 1973: 281-96.

21 McGuinness R. Association of diabetes and cataract. Br Med J 1967; ii: $416-8$.

22 Caird FI, Hutchinson M, Pirie A. Cataract and diabetes. Br Med $J$ 1964; ii: 665-8.

23 Caird FI, Hutchinson M, Pirie A. Cataract extraction in the English population. Br J Prev Soc Med 1965; 19: 80-4.

24 Burditt AF, Caird FI, Draper GJ. The natural history of diabetic retinopathy. QJ Med 1968; 37: 303-17.

25 Khan HA, Bradley RF. Prevalence of diabetic retinopathy. BrJ Ophthalmol 1975; 59: 345-9.

26 Schanzlin DJ, Jay WM, Fritz KJ, Tripathin RC, Gonen B. Hemoglobin A, and diabetic retinopathy. Am J Ophthalmol 1979; 88: 1032-8.

27 Mitchell P. The prevalence of diabetic retinopathy: a study of 1300 diabetics from Newcastle and the Hunter Valley. Aust $J$ Ophthalmol 1980; 8: 241-6.

28 West KM, Erdich LJ, Stober JA. Detailed study of risk factors for retinopathy and nephropathy in diabetes. Diabetes 1980; 29: 501-8.

29 Palmberg P, Smith M, Waltman S, et al. The natural history of retinopathy in insulin dependent juvenile onset diabetes. Ophthalmology (Rochester) 1981; 88: 613-8.

30 Segal P, Treister G, Yalon M, Sandak R, Barezin M, Modan M. The prevalence of diabetic retinopathy: effect of sex, age, duration of disease and mode of therapy. Diabetes Care 1983; 6: 149-51.

31 Constable IJ, Knuiman MW, Welborn TA, et al. Assessing the risk of diabetic retinopathy. Am J Ophthalmol 1984; 97: 53-61.

32 Donovan RJ. Prevalence of retinopathy in a diabetic clinic. $\mathrm{Br}$ Med J 1978; i: 1141-2.

33 Hockaday TDR. Diabetic maculopathy. Br Med J 1983; 286: 915-6.

34 Grey RHB, Morris A. Ophthalmic survey of a diabetic clinic. II. Requirements for treatment of retinopathy. Br J Ophthalmol 1986; 70: 804-7.

Accepted for publication 11 February 1986. 